Portland State University

PDXScholar

\title{
An Examination of Approaches to Domestic Violence Advocacy: Recommendation for Generalizable, Experimental Study
}

Melanie Stewart

Portland State University

Follow this and additional works at: https://pdxscholar.library.pdx.edu/honorstheses

Let us know how access to this document benefits you.

\section{Recommended Citation}

Stewart, Melanie, "An Examination of Approaches to Domestic Violence Advocacy: Recommendation for Generalizable, Experimental Study" (2016). University Honors Theses. Paper 291.

https://doi.org/10.15760/honors.300

This Thesis is brought to you for free and open access. It has been accepted for inclusion in University Honors Theses by an authorized administrator of PDXScholar. Please contact us if we can make this document more accessible: pdxscholar@pdx.edu. 
An Examination of Approaches to Domestic Violence Advocacy: Recommendation for Generalizable, Experimental Study

\author{
By \\ Melanie Stewart
}

An undergraduate honors thesis submitted in partial fulfillment of the requirements for the degree of:

Bachelor of Science

in

Portland State University Honors College

and

Criminology and Criminal Justice

Portland State University, College of Urban and Public Affairs:

Hatfield School of Government

Thesis Advisor

Dr. Laura J. Hickman

Portland State University 


\section{Table of Contents}

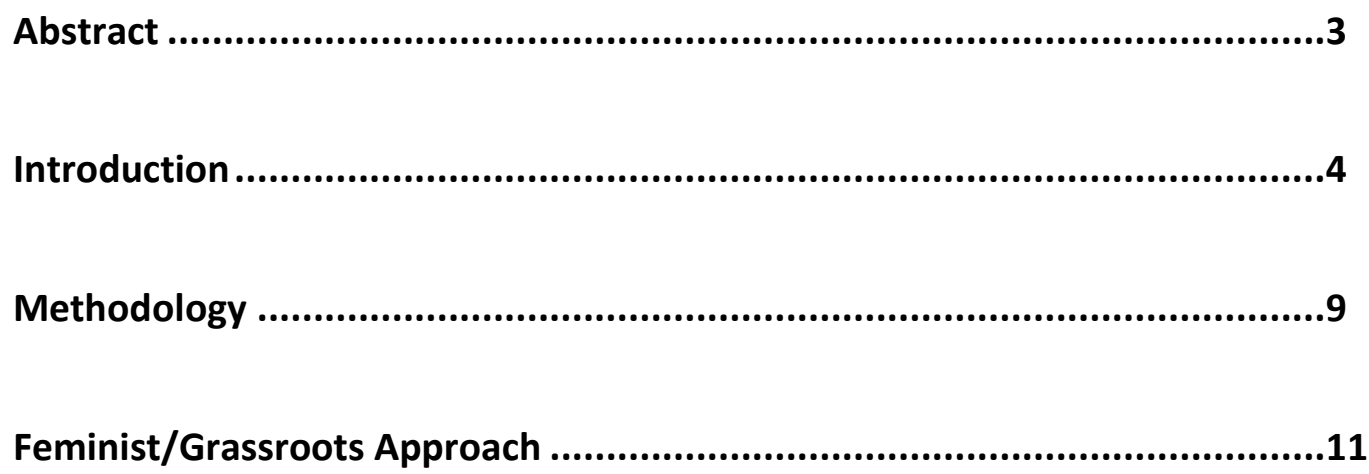

Problems, Goals \& Activities

Professional/Service Approach ............................................................17

Problems, Goals \& Activities

Discussion ................................................................................24

Recommendation for Study Design..................................................29

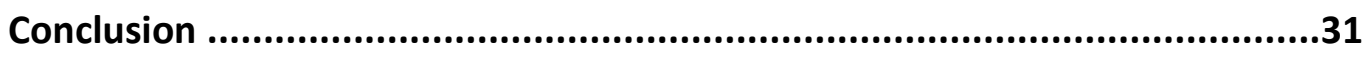

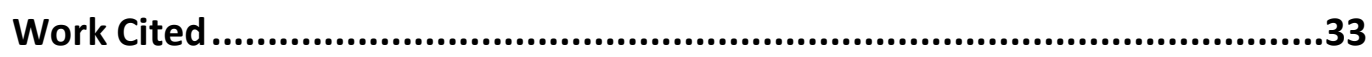




\section{Abstract}

Only since the 1970s has there been societal interest in establishing Domestic Violence (DV) advocacy to address the violent oppression of women. The catalyst which brought this issue to the forefront of social consciousness was the Women's Liberation Movement. The activism of the 1960 s civil rights movements set the stage for the Battered Women's Movement. Feminists recognized violence as a product of patriarchal society. Patriarchy, and with it personal and institutional violence, was embedded in every aspect of society. Shifting ideological and political views have influenced the evolution of DV advocacy from the grassroots activists' fight for equality, to the modern professional approach to DV advocacy. In this shift in advocacy approaches, professionalization and political goals were either integrated with or replaced entirely the culture and goals of the grassroots movement. This transformation has occurred despite limited comparative, experimental study. This thesis will recommend comparative study to explore questions of (1) whether these shifting goals have been positive for victims of DV (2) how these goals are currently measured, and (3) how they should be measured. 


\section{Introduction}

To begin the development of a cumulative body of theoretical and empirical knowledge to inform policies, a research program is needed that addresses the concerns and limitations of existing research. Such a process can be translated to other criminological problems and form the basis of a "model" for building knowledge and policy (Fagan, 1996, p. 41).

Domestic violence (DV) is variously referred to as intimate partner violence (IPV), family violence, battery, wife abuse, and spousal abuse; it is traditionally viewed as violence against women by men in an intimate relationship (Black, Basile, Breiding, et al. 2011). DV is a term encompassing numerous types of abuse which can occur within an intimate relationship. One current definition of DV states:

Domestic violence is a pattern of assaultive and coercive behaviors, including physical, sexual, and psychological attacks, as well as economic coercion, that adults or adolescents use against their intimate partners (Healey, Smith, \& O'Sullivan, 1998, p. 3).

The impact that DV has on society is evidenced by the extensive multi-disciplinary study and publication devoted to this social issue. Researchers across social science disciplines have studied individual aspects of DV advocacy, programs, response, causes, and red-flags to aid in prevention, but there is a glaring lack of experimental study in these areas. "Much recent social movement research has taken the existence of a movement as a given and investigated dynamics or processes of movement functioning" (Lehrner, \& Allen, 2009, p. 656). This paper 
seeks to explore the development of DV advocacy in the United States, and it will foreground three questions: 1) Which of the following approaches to advocacy best serve victims of DV: professional advocates using an individual-empowerment approach or grassroots advocates practicing relational-responsivity? 2) Why is a large-scale, experimental design study needed to answer the preceding question? 3) With respect to study design, what scientific methods have been considered in assessing DV advocacy service delivery and which need additional consideration?

The study of intimate partner violence is decidedly a cross-discipline endeavor which includes many contexts and specializations within the social science community. Analysis is contributed by criminological, psychological, medical, anthropological, biological, and gender studies fields of scholarly discourse within the social sciences. Gender/Feminist and Social Work scholars have been the largest contributors of data and research methodology in studying DV issues. The scope of such a broad discourse community is surprising, but justified when so many facets to this issue exist. One area of social science which presented a particularly intriguing aspect to the recommendation of experimental research design was anthropology, which studies language use and group culture (Schow, 2006). Anthropology would be a helpful lens when conceptualization has long been a dilemma for DV research because of the ideological nature of the topic. The broad DV discourse community adding to DV research can create a conundrum of focus. This paper centers the multidisciplinary discussion to emphasize a need for controlled comparative study of two opposing approaches to DV advocacy. Each approach drives organizational culture in victim advocacy across system collaborations, including law 
enforcement, courts, healthcare, and community nonprofits. The efficacy of DV advocacy will be legitimized by examining victim outcomes using controlled experimental design to study the organizational culture and process of these two approaches, that I will suggest require further study.

For the sake of continuity and clarity, gender language in this thesis will place males as perpetrators of DV and females as victims and survivors. Women have not been the only victims of DV. The National Intimate Partner and Sexual Violence Survey (NISVS) most recently completed by The Centers for Disease Control and Prevention in 2010 showed that... DV has been predominantly perpetrated against women:

About 1 in 4 women (24.3\%) and 1 in 7 men (13.8\%) have experienced severe physical violence by an intimate partner (e.g., hit with a fist or something hard, beaten, slammed against something) at some point in their lifetime (Black, Basile, Breiding, et al. 2011).

Use of this language does not seek to exclude or discount the full range of victimization that occurs across gender, social, and economic classification. The use of gender specific language is especially relevant because of the awareness that feminism, including the social movement and language created by the dialogue, has contributed to the development of DV advocacy.

In the debate over how to define an effective approach to advocacy, experts in psychology, criminology, women's studies, social work and those who study human interaction agree that DV is a complex social issue. Each study encountered throughout this thesis research has the same conclusion: "more study is necessary" (Dunn and Powell-Williams, 2007; Morgaine, 2009; Schow, 2006; Smith, 2001; Kolb, 2011). A comparative, experimental study has 
not been undertaken as of yet by criminologists, sociologists, or psychologists. Scholars from these three disciplines have been the most vocal in calling for more comprehensive study, but they have yet to produce the scope of study they themselves call for. Criminology professionals have been more effective than other social scientists at accomplishing experimental studies of qualitative data on a large-scale. This thesis will base research recommendations on the conceptualizations within the field of criminology of (1) efficacy and (2) result generalizability. Although this discipline has excelled at studying procedural response, it has failed to control for aspects of organizational culture, especially regarding responses to domestic violence (Sherman, 1992).

In his book, titled, "Policing Domestic Violence: Experiments and Dilemmas" the criminologist Lawrence Sherman (1992) critiqued the 1984 Minneapolis Experiment, that he constructed, which was a social science experiment of mandatory arrest as a law enforcement response. Sherman discusses gaps in generalizability, and points out areas of operationalization and conceptualization within the research which were overlooked. It is important to focus on the methodology of the experiment discussed by Sherman and note his reflective observations about the impact of concepts that went unacknowledged in his and subsequent experiments. Although Sherman was an "architect" of The Minneapolis Experiment, in his book he takes a hard look at concepts and perspectives all but ignored by government officials and law enforcement in framing the way results were presented and extensively used in policy decisions. 
The Minneapolis Experiment, subsequent replicated experiments, politicallyconservative family values, and the individualistic focus of policy driven by the Classical School perspective, were instrumental in the shift from grassroots to the modern professional approach to DV advocacy. The Classical School perspective assumes that people decide their actions, by considering the pros and cons (Tibbetts, 2012). Prior to this influence, the battered women's movement and resulting grassroots organizations were driven by the Positive School perspective, which asserts that people do not choose actions and circumstance, but are a product of static, societal and environmental influences (Tibbetts, 2012). Additional criticisms of DV research identify gaps that this thesis aims to address in recommending comparative study of the shift from grassroots advocacy to an emphasis on service delivery. One study warned, "In the absence of a movement analysis, victim services risk devolving into hierarchical and pathologizing interventions" (Lehrner, \& Allen, 2009, p. 657), referring to the feminist "movement" for social-change (anti-patriarchy). A presentation on batterer interventions in DV cases posited, “...criminalization policies have proliferated without consideration of the empirical evidence of their effectiveness or their unintended consequences" (Fagan, 1996, p.5).

This thesis seeks to join the multi-disciplinary voices calling for large-scale, comparative study of the efficacy of these two approaches to DV advocacy, and an examination of the outcomes for victims with a greater emphasis on careful conceptualization and controlled variables. Lawrence Sherman, a Criminologist, Lenore Walker, a Feminist/Social Work researcher, and an extensive list of professionals across the disciplines of psychology, healthcare, social work, political science, criminology, sociology, and countless other scholars have conducted research in the area of DV response and laid the basis for the recommendation 
for comparative, experimental study in this thesis. These researchers have also put up caution signs for future researchers to attend to regarding issues of innovation-stagnation, in addition to the admonition that all researchers must be ever vigilant to the pitfalls of biased research goals which can be damaging to objective experimentation.

This thesis will discuss the methods and framework to propose large-scale experimentation of these two approaches to DV advocacy. The empirical data surrounding this social issue, as it applies to victim outcomes, has been primarily non-experimental, programspecific, and fixated on individual organizations, programs or interventions. Criminology research has been successful in structuring social experimentation on a large scale, with adequate funding, and using comparative controlled variables. This type and scope of research data needs to be available to most rigorously assess the efficacy of current DV advocacy models.

\section{Methodology}

The primary body of research material for this thesis was acquired using Portland State University (PSU) Library database student access. The chosen section of the Library service was Google Scholar and EBSCOhost search engine to search Academic Search Premier, which yielded relevant material from collections including Science Direct, Sage Journals, SpringerLink, and JSTOR. Other resources used in this research were internet-accessible government databases such as The National Criminal Justice Reference Service (NCJRS), Bureau of Justice Statistics (BJS), The National Institute of Justice (NIJ), Center for Disease Control (CDC), and The Office on Violence Against Women (OVW), which administers funding allocations and oversight 
for The Violence Against Women Act (VAWA). Google general search was used for clarification of literal term definitions as needed. Additional material was gained through purchasing books which were often cited in reference to the earliest origins of the battered women's movement activities and operations, but were not readily available via internet sources. In some cases, conceptualization of feminist and political concepts was gained through this author's study of material from Portland Community College (PCC) and PSU coursework.

To build a framework for comparing and contrasting two approaches to DV advocacy, research was placed the into a Logic Model format, at the guidance of the thesis Adviser. This step served to focus and define the problems, goals, objectives, and activities of each approach to DV advocacy, and was accomplished through systematic analysis for review of the qualitative research studies, scholarly books, papers, and articles published, including this author's advocacy training and observations. The conceptualization of terms, practices, and models common to DV advocacy was done through examining definitions and the ideological interpretations and variations put into practice by historical and modern advocacy practitioners and organizations.

DV terminology is varied and debated. This thesis will use the term DV. Other terms applied to DV include, Intimate Partner Violence (IPV), which has gained popularity as the preferred term because it more accurately encompasses the diversity of victims and perpetrators. A few others that apply, though not an exhaustive list; family violence, battered spouse/wives, intimate terrorism, and spousal abuse. There has been inconsistency in the 
language used to label and discuss DV advocacy. This makes conceptualization of terms complex yet crucial to a foundation of comparative analysis.

This thesis will examine the historical context of the grassroots feminist approach to advocacy, in addition to reviewing the first-hand published accounts of grassroots feminist and "Battered Women's" advocates at the birth of the movement. The research will show how these societal and legal developments have shifted the organizational culture of the approaches to DV advocacy over time to the modern professional approach. This thesis will discuss the positive and negative effects that these shifts have had on victim and survivor outcomes and the organizations charged with assisting them. Finally, it will conclude with a discussion of the criminological, sociological, and psychological research findings and methods that alternatively agree and disagree with the modern approach to DV advocacy and the study of victim outcomes. Using these methods, this thesis intends to frame the scope of the social and institutional issues of DV using analytic methods encompassing the historical, social and political context of two approaches to DV advocacy, the culmination of which will support the argument for a comparative, experimental research design recommendation.

\section{Feminist/Grassroots Approach}

The historic organization of the feminist approach to DV advocacy came in the form of the battered women's movement. The success of the 1960s-70s Civil Rights movements drove grassroots feminists to respond to the issue of DV. It's notable that attempts to make DV a human rights issue or violation have failed (Morgaine, 2009). The objective of the battered women's movement approach to advocacy was to change the power differential of women in 
society, to improve the lives of women, and to provide responsive services to individual women experiencing abuse. Early advocates for victims of DV emerged from and operated under feminist ideology. The battered women's movement began soon after civil rights activism brought many social issues bubbling to the surface of society's social conscience. Susan Murray (1988), a Sociology and Interdisciplinary Social Sciences Professor, frames the feminist approach ideology within the context of battered women's shelters and the grassroots organizations initiated by feminists who identified the need for advocacy and activism. The Battered Women's Movement sought to combat violence against women. Advocates opened their homes, built shelters founded on feminist ideology, and birthed the battered women's movement. Murray explains that these early DV shelters were built upon "self-help and peer" frameworks rejecting hierarchal and patriarchal structures (Murray, 1988). Hierarchal structures were seen as contributors to the power imbalance defining feminist arguments and perpetuating violence against women. Liberation feminists formed the foundation for the feminist-grassroots approach to advocacy for battered women.

\section{Problems, Goals \& Activities}

First and foremost, grassroots (liberation/radical) feminist DV advocates focused their work on the social problem of battered women's experience in society. "This sociopolitical analysis of domestic violence motivated dual goals for the nascent social change movement: the pursuit of fundamental social change and the creation of shelter and services to provide immediate safety for victims" (Lehrner, \& Allen, 2009, p. 657; Schechter, 1982). A core belief which drove practices maintained that women will be at risk of battering as long as they remain 
subordinate in a patriarchal society. The acceptance of male-dominated political discourse and system structures, which oppressed both the professional and private lives of women, prompted advocates to take action. Actions of the movement were focused on changing maledominated political discourse, societal norms, and the daily consequences women faced as a result of patriarchal culture.

Many long-standing female stereotypes persist which affect the treatment and representation of women in social and professional positions of influence. One of the most detrimental gender stereotypes placed on women is the denial of their ability to participate in leadership roles. Women remain underrepresented in legislative and law enforcement positions. "In 2016, 104 (76D, 28R) women hold seats in the United States Congress, comprising $19.4 \%$ of the 535 members; 20 women (20\%) serve in the United States Senate, and 84 women (19.3\%) serve in the United States House of Representatives" ("Women in the U.S. Congress 2016 | CAWP," n.d.). Exclusion from political roles, the use of stereotypical language, and the legitimization of male-centric values directly affect policy and procedural decisions and shape the culture surrounding the response to DV.

Grassroots advocates postulate that it is not the individual batterers who are wholly to blame for DV, but the construction of the male-dominated power differential in every tier of society, government, religion, media, economics, law enforcement, workforce, education and ultimately family structures. These individual and socio-structural barriers perpetuate accepted gender norms which condemn the abuse of women while simultaneously denying the influence and history of social contributions to the subordination of women in society and the family unit. 
Cultural attitudes that contribute to IPV (DV) stigmatization include judgment, blaming, minimizing the extent of the problem, and stereotypes about the types of people who are abused. Together, these components can make it more difficult for victims to seek help (Murray, Crowe, \& Akers, 2016).

Women who faced DV were historically seen as over-emotional and were thought to have "over-reacted" to a general marital disagreement. The prevailing attitude regarding DV was that women should "work it out" with their husbands. Women and children were seen as merely property supported by the "head of the household." They were seen as weak, inferior, and not as capable as the man of the house. As a result of these socio-structural constraints, women and their children were wholly dependent on the financial support of the patriarch of the family. This not only played out in the financial lives of women, but also shaped their very identities. Religion and social gender normative language lauded the virtues that to be submissive was to be feminine, good, righteous, and ultimately womanly.

Early advocates that took action to address these inequities were comprised of survivors of DV and outspoken feminist activists. They protested established gender norms, rallied to change legislation, and put pressure on law enforcement and District Attorneys to take DV seriously as a crime. Advocates under this approach also took roles as activists in calling for equality. The battered women's movement began as a civil rights call for equality and radical demands for cultural change. Demands for cultural and systemic changes were made by "Radical" or "women's liberation" feminists who were determined to overthrow patriarchy entirely. They believed it was responsible for the oppression they saw in women's lives, and 
that to stop DV they would need to reshape patriarchal social and professional systems. This was seen as central to ending the power and control dynamic indicative of DV. By addressing the larger social problems of women in society through activism, they hoped to bring awareness and active social change through the movement.

Other problems these early grassroots advocates sought to address were the economic, personal, and social disempowerment of DV victims. The largest reason that women and children suffered homelessness was because of fleeing abuse. Initial attempts to address the displacement of women and children by DV were led by the movement, and began with battered women's shelters that rose primarily from white, feminist, advocates/activists, and DV survivors. "Marjory Fields, for example, objected to the idea of a wife going into hiding while her assailant was free, but she 'received too many calls from women huddled in phone booths with their children, asking where they should go' to question the urgent need for shelters" (Pleck, 1987). It is this grassroots community response to a primarily private-hidden social issue and the holistic, non-hierarchical structuring of these shelters that is a focus of much research and debate about effective advocacy. In the earliest shelters, "advocates operated as a collective and divided administrative responsibilities. A founder of the shelter said, 'A shelter is not a treatment center; residents are not described as clients, battering is not described as a syndrome'" (Pleck, 1987). Shelters were not seen as a solution to the problems facing victims of DV: “A key goal of domestic violence law and policy must be to address the institutionalized economic vulnerability of women in society" (Bailey, 2010). In St. Paul, Minnesota, a group of women who created a legal helpline noticed that women who "required emergency housing 
called the group's telephone hotline. Because there was no emergency housing available, some of the staff began to house these callers in their own apartments" (Pleck, 1987).

The scope of assistance available to battered women at the dawn of the 1970s included family, friends, and clergy, with little to no support from healthcare providers and law enforcement intervening only in cases of severe physical abuse (Fagan, 1996). Family and friends often responded in a similar fashion to law enforcement. Incidents of abuse were seen as isolated, and either the product of alcohol, frustrations at work, or placed on the shoulders of the victim for "nagging." This void was filled by the social support that was provided by survivors and women helping each other in peer and self-help settings.

Feminists saw the safety issues that a lack of legal protections, both criminal and civil, created. Divorces were difficult to obtain and dangerous for women and their children. The earliest DV advocates staffed legal information help lines, while activists brought civil suit against police departments for failing to respond to calls for help from victims. The need for representation in obtaining divorces was quickly apparent, even when greater police response and restraining orders were available. Although greater access to restraining orders was welcome, "few studies have examined the effectiveness of restraining orders in reducing the incidence of domestic violence, and those few studies have been nonexperimental or quasiexperimental with designs that weaken any conclusions about their effectiveness" (Fagan, 1996, p. 24). Advocates formed support groups, "accompanied battered women to courts and assisted in pressing criminal charges against their husbands" (Pleck, 1987). Despite achieving greater support from law enforcement and other government systems, liberation feminists still 
believed that solutions required radical advocacy for reform at law enforcement, court, and legislative levels. Police departments continued to rely upon subjective criteria when making arrest decisions. One such evaluation practice "relied on a 'stitch rule'-arresting an abusing husband only if his wife had been injured badly enough to require a specific number of sutures" (Pleck, 1987, p.186). Activism, while an arguably powerful tool for feminism, caused complications when asking for support from law enforcement and lawmakers. Gains were made, and with each adaptation by government authority (legislation or law enforcement), "the moral authority of messages from women's groups and community-based organizations was reinforced" (Fagan, 1996, p. 38).

Although the battered women's movement had grown in momentum, it quickly transitioned in the 1980s into the modern professional approach, leaving few remnants of the feminist grassroots approach in the form of underground networks, and scattered outspoken advocates/activists.

\section{Professional Family Violence Approach}

Early professional approach shelters and social service organizations were founded on the traditional branch of $2^{\text {nd }}$ wave feminism, whose methods originally centered on the goal of increasing the participation of women within existing established systems. These hierarchical, professionally structured organizations believed that recognition by the government (lawmakers and law enforcement) was the primary key to helping victims of DV. This group set the operational structure for modern DV/IPV service organizations. The decision to adopt and integrate certain status expectations of "professionalism" would create further divide between 
the liberation (grassroots advocacy) feminists and the traditional group. The advocates operating under this approach were able to inspire institutional shifts in the response to DV victims.

Police departments adopted proarrest or mandatory arrest policies. Domestic violence units were formed in prosecutor's offices, and treatment programs for abusive husbands were launched in probation departments and among community-based groups. Reforms in protective and restraining order legislation enabled emergency, ex parte relief that included not only no-contact provisions but also economic and other tangible reliefs for battered women (Fagan, 1996, p. 9; Grau, Fagan, and Wexler, 1984).

\section{Problems, Goals \& Activities}

The objective of the professional approach to advocacy is to guide and educate survivors of DV towards decisions in breaking the cycle of violence and improving the physical and psychological health of victims/survivors of DV. Labeling language is seen as a way to empower victims. Victims are immediately "survivors" upon seeking assistance at any stage of the process. This projects agency onto the victim, and demonstrates the confidence advocates have in them to be capable of making decisions to keep themselves and their children safe from abuse. Findings from a study to gauge the current knowledge of and engagement in social change activism by DV advocates across a Midwest State found that, "In some cases these participants (professional advocates) suggested that the ultimate goal is to change the victims to end domestic violence" (Lehrner, \& Allen, 2009, p. 663). This is in line with assertions made by psychologists and political culture which support a view of DV as a product of individual 
choice: victims chose to enter and/or remain in relationships or marriages and the abuser chose to be abusive. This view is also supported by a criminological stance which delineates offenders and victims by explicit criteria.

Acting upon this logic, the resulting response to victims who choose to marry, remain with, or go back to abusers indicates that they need psychological treatment and education to recognize healthy relationships and to change decision-making patterns. Proponents of the professional approach thus consider the main priorities of DV advocacy to be the mental health and emotional stability of victims and perpetrators of abuse. Professional approach advocates frame DV as a failure of the individual to recognize and participate in healthy relationships. This primary definition of the problem of DV informed the professional approach's definition of the range of issues facing victims.

In the 1980s, a pioneer of the professional advocacy approach, Ellen Pence, put forth the "Duluth Model" and other innovations in both victim advocacy and batterer intervention/treatment ("The Duluth Model - What is the Duluth Model?," n.d.). One such innovation sparked the modern co-located service model, built upon Pence's vision of coordinated community response. Under this vision, advocates coordinate with systems of healthcare, social services, and law enforcement to respond to DV. These partnerships with medical professionals provide connections co-located with, or in some cases advocates are employed by, hospitals and care providers to respond to victims who are identified when seeking care. Victims are often identified by these providers when seeking care for injuries, symptoms of chronic stress, mental health, or from family practitioners, dentists, and others. 
Although DV had long been recognized as a behavioral cycle, the Duluth Model's "Power and Control Wheel" defined and identified the cycle of violence as a real and legitimate aspect of the context of DV, creating a tool and symbol around which community and institutional advocates could rally. Professional advocates believe that interrupting and informing victims' understanding of their role in the cycle will empower victims to end abuse.

Counseling for survivors therefore became a key program of DV service organizations, based on data offered by psychologists and an orientation toward the goal of empowerment. Once counseling became a preferred program, efforts to frame DV as a medical concern gained momentum. Professional advocates believe in the importance of illuminating recognition of DV by survivors who may be too wrapped up in the cycle to clearly understand the dangers of remaining in a violent relationship. There are both obvious and hidden medical concerns for DV victims: physical injuries, maintained high stress levels, pregnancy and reproductive health issues, to name a few. These concerns, in addition to the high lethality rate for women by violent intimates, motivate professionals to encourage victims to "leave" a violent partner.

Both advocates and legal professionals consider the primary safety problem of DV to be the survivor's choice to remain in an abusive relationship or return to an abusive relationship after an incident of arrest or assault. Professional advocates' preferred approach to addressing this safety problem is to encourage a survivor's personal choice to be safe (stay/leave abuser), with an emphasis on leaving. Increasingly, advocacy service organizations strongly encourage separation from the violent partner, and some use language that imply this is a condition for the receipt of certain services. For example, meeting this condition may be a preferred 
prerequisite in order to be eligible to participate in support group counseling. When a survivor evaluates this safety problem and concludes that the safest choice is to remain with an abusive partner, they often receive blame for this choice and in some cases are even villainized for failing to extract themselves. If an arrest, investigation, or criminal proceeding is initiated, or in some cases if simply emotional or physical abuse is identified, this will trigger an immediate Child Protective Services' (CPS) investigation. These investigations also pressure survivors to leave violent partners due to a possible risk of losing custody of their children based on CPS accusations of placing their children in an unsafe living environment.

Although leaving the abuser is the preferred course of action, there remain acknowledged barriers to safety. There are limited shelter beds for DV survivors.

It also has been estimated that nearly half of all homeless women and children have fled violence in the home. When women with children do take the economic risk to escape abuse, they often find they are punished for their lack of resources with findings of child neglect and further state scrutiny. Thus, some of the current policies in the criminal justice system may actually be putting some women in more danger due to their economic circumstances (Bailey, 2010, p. 159).

This reality creates a conundrum for professional advocates. While their objective is to educate and empower, they also view survivors as individuals accountable for their choices. Job readiness and skill building, financial training programs, and time limits for receiving resources such as shelter space or counseling services discourage survivor dependence and maintain resource availability for high risk survivors. Both empowerment goals and the scarcity of 
resources contribute to policies where "many domestic-violence shelters impose a thirty-day stay limit on families to allow space for individuals in immediate danger" (Richards, Garland, Bumphus, \& Thompson, 2010).

The recognized gaps in both criminal and civil legal protections motivated advocacy goals of guiding survivors through legal steps to hold offenders accountable and to separate the survivor from the abusive partner. The prevailing belief during the conservative political shift which included a law-and-order focus, was that holding individual abusers responsible for their violence was the optimal way to combat IPV. Criminal legal protections for DV victims have been implemented since the 1970s, but criminal law has not been able to balance a focus on physical abuse with the totality of controlling behaviors which encompass DV. Criminal statutes have evolved to include sexual assault (marital) and stalking and are in place to deter and punish behaviors deemed harmful to society. A publication produced as "a safety \& empowerment guide for battered women," funded by The Office of Criminal Justice Planning of California, explicitly stated "If you have just been beaten, you can call the police and upon seeing evidence of visible injury, they will arrest the abuser. If you have a restraining order and the abuser violates it, you should call the police ... they will arrest him" (Cuevas, Dankowski, Giggans, \& Ledley, 1989). Please note, this is an unabridged quote from this guide and remains the criteria for police intervention. Despite awareness campaigns, targeted training, integrated police advocacy programs, feminist activism, the Minnesota (Duluth) Power and Control Wheel, and the empirical knowledge gained through social science research, DV is not an arresting offense except under physical conditions. 
Even when a criminal prosecution is possible, there are limited resources available to provide full representation in the often parallel civil case. Legal remedies include the arrest and treatment of offenders, CPS Family Abuse Protection Act (FAPA) otherwise known as restraining orders or ex parte orders of protection, and no contact orders. DV advocacy organizations assist with forms, and safety planning. However, advocates cannot offer victims assistance beyond filing unless the organization has a licensed attorney on staff, many of which do not. Legal representation is necessary in civil cases but often difficult to obtain for victims of abusive control. Because abusers often discourage victims from working outside of the home, victims lack the financial resources that the abuser has to hire legal representation. Once a FAPA order has been filed, a victim of DV is responsible for obtaining a private attorney if the order is contested, as well as for subsequent civil legal issues such as divorce and/or child custody. A common misconception is that when a DV victim reports abuse to law enforcement and the District Attorney (DA) tries and convicts the offender, the victim does not need a lawyer. This often creates an untenable problem for the victim, especially if no conviction is made or if the charges were minor or misleading. "Access to appropriate services and maintaining confidentiality are critical both for response to violence as well as recovery for the survivor. One strategy to improve access is co-located, multi-disciplinary service centers that include mental health, legal, economic, housing and other related services for survivors" (Black, Basile, Breiding, et al. 2011). 


\section{Discussion}

In spite of the two approaches' shared goals of empowerment, safety, and health, there are distinct differences in their identity and process goals. Feminist identity goals are to work together, inclusively in the attainment of empowerment, safety and health for all, while professional goals center on applying treatment and services as a provider of a product to an individual. There are paradoxically, similarities and differences across the identity, process, and contextual goals of each approach. At the core of this paradox is each approach's use of language and their view of the victim (Bailey, 2010). Each approach's understanding of victims is presented in this thesis as follows:

\section{Grassroots Feminist Advocacy}

Victims have no responsibility, choice or personal agency in their victimization. Victims are not necessarily helpless or weak or appear to others as such. The strongest bodybuilder can be robbed, and the strongest victims are still victimized. Victims need compassion and assistance to provide for their needs, including financial, housing, medical, legal, psychological, and community support. Victims will heal when their needs are met. This, in its simplest form, is the grassroots feminist, 1970s, women helping women, peer model of individualized advocacy.

\section{Professional Service Advocacy}

Victims are treated as survivors the moment they report abuse, and are expected to make decisions based on "empowering" information, including referrals and choices 
given by advocates. Another facet of this approach to advocacy is the lack of help offered unless a victim has indicated that she is ready to be empowered by reporting the abuse and has initiated steps to separate from the abuser. In reality, leaving her abuser indicates she is already empowered, and advocacy is then taking credit for empowerment already belonging to the victim. This is also used by advocates to personally and professionally deflect responsibility. Studies have observed the oppositional goals victim service advocacy has with empowerment and personal agency. Framing victims as individuals whose choices can be "empowered" discounts the lack of agency at the core of victimization (Schow, D. 2006 and Smith, S. E. 2001). Advocacy agencies and counselors use empowerment to work from a model whereby the victim has agency over their choices effectively denying their victimhood (Dunn \& PowellWilliams, 2007; Kolb, 2011). In this way, empowerment creates conflict in the modern professionalized, medical, welfare-to-work advocacy model.

In the 1980s, a shift occurred in the battered women's movement. The movement transformed from feminist activism, advocating for equalizing social and legal reforms, to conservative crime control responses, focused on male-dominated, Christian-defined family values (Ferraro, 1996). The simultaneous agreement/disagreement between predominantly white conservative condemnations of wife-beating were pitted against the preservation of male-dominated hierarchies. The branch of the movement that would be labeled "radical" feminist ideology, condemned participation in patriarchal systems, while mainstream $2^{\text {nd }}$ wave 
feminism embraced this compromise. This is the point at which the two approaches become distinct from one another.

Feminist advocates saw the mutual benefits of watering down feminist activism and the battered women's movement, but many also feared the changes. Ultimately, this steered the progression from a grassroots social movement to a criminological effort and the modern empowerment model (empowerment in this context meaning individual responsibility and agency). Feminist ideology demanded an equalizing response to DV, but were divided between radical and mainstream approaches. The government of the 1980s held a belief that a crime control response alone would solve the issue. Sparked by these values, the conservative-led government assumed the role of rescuer. The rescue efforts, in this case, took the form of government and research funding. The research that supported politically championed crime control responses to DV led to greater law enforcement engagement, and federal funding dollars (Sherman, 1992). The rescue came at a steep price to liberation/grassroots feminist goals, which sought to change the culture of patriarchal-hierarchical systems that perpetuate male dominance in the public, private, and financial lives of women. The battered women's movement, as a civil rights call for equality and radical demands for cultural change, was derailed (Schechter, 1982).

The professionalization of grassroots organizations and a capitalist-competition model for "awarding" funding has molded and transformed the organizational development and culture that initiated the battered women's movement. Welfare reform, which encouraged all social services to adopt time-pressured criteria for entering or re-entering the workforce, were questionable policies that presented added risks to service recipients in cases of DV. Homicide 
statistics gathered in 2010 show "Of the 3,032 homicides involving female victims in 2010 (the most recent year), 39 percent were committed by an intimate, 37 percent by a nonintimate and 24 percent by an offender with an unknown relationship to the victim" (Catalano, 2013).

The "service agencies" operating today replaced the grassroots battered women's movement. The "...expansion of victim services and increased funding base has had profound consequences for the movement, (re)shaping philosophy, promoting professionalization, and potentially curtailing larger social change efforts" (Lehrner, \& Allen, 2009, p. 661). Former social-change advocacy groups currently operate under hierarchical norms of quasi-medical policies and production-line measures of success. Accomplishments are defined by numbers served, versus subjective quality of empowerment and attainment of long term goals by victims.

This dilemma is partially the result of a strategy for knowledge development in which well-intentioned reforms were mounted but with weak evaluation designs that often were introduced after programs were designed and launched (Fagan, 1996, p. 41). These transformations from grassroots response to professionalism, criminalization, and public health concerns took place with evaluation, but without rigorous-comparative research. "Research on the effects of legal sanctions has been limited by weak research designs, a narrow range of theories, poor conceptualization of potential interaction effects and subgroup differences, weak interventions and sanctions, and implementation problems" (Fagan, 1996, p.40). Because of the difficulty and cost associated with generalizable, experimental research of this type, there are questions that have only been addressed in part or through ideological 
lenses. Have the transformations of DV advocacy been positive for victims of DV? How have the shared goals to serve victims of DV been conceptualized consistently to establish benchmarks for successful advocacy? How should efficacy/success be measured? Who and what are considered trustworthy sources regarding the indicators of efficacy? Survivors? Advocates? Researchers/Observers?

Funding dollars that came with welfare reform and VAWA directives have solidified an often contradictory culture of individual accountability with victim support (Smith, 2001; Schow, 2006; Dunn and Powell-Williams, 2007). A study titled "Women's Experiences of Violence and Seeking Help" sought to question which services women used, found most helpful, and whether they perceived they had adequate access to those services. The researchers hoped to bring to light gaps in the research of the help-seeking behavior of female victims of violence. Self-identifying, voluntary, snowball sampling methods were used to gather participants. The study observed that victimized women did not place the greatest importance on the services deemed necessary by providers and they also perceived greater gaps and barriers that providers did not identify. While services available were focused on providing counseling and emotional empowerment, interviewees reported their high priority needs as physical and practical (Postmus, Severson, Berry, \& Yoo, 2009). This article substantiates a crucial point of this thesis by discussing the contrast between victim and provider perceptions of service needs. Several areas of treatment research have recognized the importance of "responsivity" of different types of individuals to various interventions (Fagan, 1996, p. 37; Andrews et al., 1990). Researchers have attempted to qualify the efficacy of sanctions and 
treatments but have not been successful in accurately capturing the reliability of treatment effects. Clinical trials and experimental research for treatment interventions are rare across disciplines because of the ethical implications of denying treatment. Treatment or targeted program research has the added disadvantage of small sample size limitations, which restricts generalizability. The three main reasons for ineffective research are: "the embedment of domestic violence in complex social and individual contexts, weak research designs and limitations on policy experiments, and the theoretical issues in male violence" (Fagan, 1996, p. 25).

\section{Recommendation for Study Design}

Random assignment to both causal comparison groups (each approach) is central to an experimental design. "There are other limitations on research design that weaken empirical findings. Although experiments represent a "gold standard" of social research, there are many circumstances in which random assignment is neither practical nor ethically justifiable. In particular, untreated control groups are not tenable when victim safety is at risk" (Fagan, 1996, p.36). In the comparative, experimental design this thesis recommends, the random assignment of advocates to each approach can be achieved via binary, 1-2, random number generation. Admittedly, previous training will be a factor, but research has an obligation to acknowledge bias when disseminating results. Randomization of the victims/clients/survivors will be based upon a daily alternating schedule. For example, on Monday victim one will be assigned to the "Family Violence Services Department" advocacy section, and victim 2 will be assigned to the "Grassroots/Mentorship/Victim Centered" advocacy section. 
Within each section (approach), separate training programs will be conducted with advocates. The independent variable of the approach to advocacy encompasses not only the direct training received by the advocates, but also the organizational leadership or decisionmaking process. The organizational structure will mirror the current professional services approach, including a hierarchical chain of command which gives an Executive Director final approval of decisions about policy and procedure. The Grassroots/Mentorship/Victim Centered decision-making structure will be a peer-support collective approach to policy and procedure, within a shared-power organizational culture. The advocates operating under each approach will have equal access to resources, community partners, and support staff, such as a receptionist and office administrators. Location will serve as an additional controlled variable. By co-locating the two approaches in one location, randomization of victims seeking assistance is easily achieved through a simple alternating probability sampling method.

An argument could be made that an experimental study design is not the most efficient or cost effective method to utilize existing organizational and community resources. It is possible that a non-experimental design utilizing existing advocacy programs and advocates could produce unbiased results. However, an experimental design provides conditional controlled variables that are impossible with nonexperimental. By controlling variables such as advocate training, procedure, and the supervisory structure the advocates work under, conditions such as the level of autonomy of the advocate can be controlled.

The use of randomly assigned advocates to each approach increases the reliability and the validity of results. Reliability is increased through uniform training and clearly defined 
operations, which will minimize subjective input advocates add in their work. Validity is supported by randomization of both the advocacy approach and the victims seeking assistance.

\section{Conclusion}

I am a survivor of DV. In the summer of 2007, my then-husband strangled me nearly to unconsciousness and flung me by my hair down a flight of stairs. I didn't leave or call the police until 3 years later. The reasons I didn't leave were numerous, but one primary reason was that I knew advocates could not replace the sole breadwinner for my family and that they would not shield my daughter from her father.

I have talked with many survivors and children of survivors, hearing them lament the same difficulties I encountered once I sought help. These criticisms include covert and overt victim blaming language, policies that create barriers, and a lack of responsive solutions and resources. I recognized the subjectivity of these criticisms and sought out professionals in leadership positions to ask them, if the populations they seek to serve are discussing these issues, "Why are survivors not present at every level of DV service policy creation?" The answers were surprising. They were thinly veiled attacks on the character, decision-making skills, resilience, and mental stability of survivors. I was overcome with questions. If these survivors and I saw the flaws and gaps in advocacy, and felt we were being dismissed, who else was challenging modern advocacy approaches? Were experts in the social science disciplines studying the barriers and culture of shame in ways more relevant than the results of exit surveys? 
I have witnessed and participated in the current form of data collection, as a survivor, nonprofit founder, and advocate volunteer. They amount to "shopper surveys" given to survivors, and sometimes advocates at the moment of and completion of a program or receipt of services. This poor methodology does little to provide much more than headcounts and demographic information, and does not adequately research survivor impact and outcomes. These revelations, along with others, led me, and co-founder Rachelle Scheele to start, with the support and input of fellow survivors, Survivor Collective Alliance Reaching Society (SCARS). Every time survivors come together, I have seen understanding, compassion and a drive to advocate for others that cannot come from a training seminar or professional certification. 


\section{References}

Bailey, K. D.. (2010). Lost in Translation: Domestic Violence, "The Personal is Political," and The Criminal Justice System. The Journal of Criminal Law and Criminology (1973-), 100(4), 1255-1300. Retrieved from http://www.jstor.org.proxy.lib.pdx.edu/stable/25766125

Black, M.C., Basile, K.C., Breiding, M.J., Smith, S.G., Walters, M.L., Merrick, M.T., Chen, J., and Stevens, M.R. (2011). The National Intimate Partner and Sexual Violence Survey (NISVS): 2010 Summary Report. Atlanta, GA: National Center for Injury Prevention and Control, Centers for Disease Control and Prevention.

Boruch, Robert F. (1994). "The Future of Controlled Randomization Experiments: A Briefing." Evaluation Practices 15:265- 274.

Campbell, Donald T. (1969). "Reforms as Experiments." American Psychologist. 24:409-429.

Catalano, S. (2013). Intimate Partner Violence: Attributes Of Victimization, 1993-2011. Retrieved May 20, 2016, from http://www.bjs.gov/index.cfm?ty=pbdetail

Cuevas, C., Dankowski, K., Giggans, P., \& Ledley, E. (1989). Surviving Domestic Violence: A Safety and Empowerment Guide for Battered Women. NCJRS - Citizen Involvement Material. doi:https://www.ncjrs.gov/pdffiles1/Digitization/120508NCJRS.pdf

The Duluth Model - What is the Duluth Model? (n.d.). Retrieved May 19, 2016, from http://www.theduluthmodel.org/about/index.html

Dunn, J. L., and Powell-Williams, M. (2007). "Everybody Makes Choices": Victim Advocates and the Social Construction of Battered Women's Victimization and Agency. Violence Against Women, 13(10), 977-1001. http://doi.org/10.1177/1077801207305932

Fagan, J. (1996). The criminalization of domestic violence: Promises and limits. Washington, D.C.: U.S. Dept. of Justice, Office of Justice Programs, National Institute of Justice.

Ferraro, K. J. (1996). The Dance of Dependency: A Genealogy of Domestic Violence Discourse. Hypatia, 11(4), 77-91. 
Grau, Janice, Jeffrey Fagan, and Sandra Wexler (1984). "Restraining Orders for Battered Women: Issues in Access and Efficacy." Women and Politics 4:13-28.

Healey, K. M., Smith, C., \& O'Sullivan, C. S. (1998). Batterer intervention: Program approaches and criminal justice strategies. Washington, DC: U.S. Dept. of Justice, Office of Justice Programs, National Institute of Justice.

Kolb, K. H. (2011). Claiming Competence: Biographical Work among Victim-Advocates and Counselors. Symbolic Interaction, 34(1), 86-107. http://doi.org/10.1525/si.2011.34.1.86

Lehrner, A., \& Allen, N. E. (2009). Still a Movement After All These Years?: Current Tensions in the Domestic Violence Movement. Violence Against Women, 15(6), 656-677. http://doi.org/10.1177/1077801209332185

Morgaine, K. (2009). "You Can't Bite the Hand ...": Domestic Violence and Human Rights. Affilia, 24(1), 31-43. http://doi.org/10.1177/0886109908326742

Murray, S. B. (1988). The Unhappy Marriage of Theory and Practice: An Analysis of a Battered Women's Shelter. NWSA Journal, 1(1), 75.

Murray, C., Crowe, A., \& Akers, W. (2016). How Can We End the Stigma Surrounding Domestic and Sexual Violence? A Modified Delphi Study with National Advocacy Leaders. Journal of Family Violence, 31(3), 271-287. http://doi.org/10.1007/s10896-015-9768-9

Pleck, E. H. (1987). Domestic tyranny: The making of social policy against family violence from colonial times to the present. New York: Oxford University Press.

Postmus, J. L., Severson, M., Berry, M., and Yoo, J. A. (2009). Women's Experiences of Violence and Seeking Help. Violence Against Women, 15(7), 852-868.

http://doi.org/10.1177/1077801209334445

Richards, T. N., Garland, T. S., Bumphus, V. W., \& Thompson, R. (2010). Personal and Political?: Exploring the Feminization of the American Homeless Population. Journal Of Poverty,14(1), 97-115. doi:10.1080/10875540903489496 
Riecken, H.W., R.F. Boruch, D.T. Campbell, N. Caplan, T.K. Glennan, J.W. Pratt, A. Rees, and W. Williams. (1974). Social Experimentation. New York: Academic Press.

Schechter, Susan (1982). Women and Male Violence: The Visions and Struggles of the Battered Women's Movement. Boston, MA: South End Press.

Schow, D. (2006). The Culture of Domestic Violence Advocacy: Values of Equality/Behaviors of Control. Women and Health, 43(4), 49-68. http://doi.org/10.1300/J013v43n04 04

Sherman, Lawrence W. (1992). Policing Domestic Violence: Experiments and Dilemmas. New York, NY: The Free Press.

Smith, S. E. (2001). A Wolf in Sheep's Clothes? How Welfare Reform May Threaten Domestic Violence Services. Affilia, 16(4), 432-446. http://doi.org/10.1177/08861090122094352

Tibbetts, S. G. (2012). Criminological theory: The essentials. Los Angeles: SAGE.

Women in the U.S. Congress 2016 | CAWP. (n.d.). Retrieved May 19, 2016, from http://www.cawp.rutgers.edu/women-us-congress-2016 